\title{
Analysis on the Farmer Households Demand of Agricultural Social Service - A View of Before Planting and After Harvesting
}

\author{
Di Chen ${ }^{1, a}$, Ying Xue ${ }^{1, b}$, Lu Sun ${ }^{1, c}$ and Jie Lv ${ }^{1, d *}$ \\ ${ }^{1}$ Shenyang Agricultural University, Shenyang 110866, China \\ aChendi19831213@163.com, b18842463211@163.com, c13555892633@163.com, \\ djieluesy@163.com \\ *The corresponding author
}

Keywords: Farmer households; Demand; Agricultural social service

\begin{abstract}
China is a traditional agricultural country. As agriculture has been in a new stage of modern agricultural development, the analysis on the demand of agricultural social service is the key factor to promote the development of modern agriculture. Based on the above analysis, we surveyed 24 villages in Liaoning Province, and conducted the questionnaire survey of farmer households with the relevant requirements on the demand of agricultural social service (before planting and after harvesting). The field survey method and descriptive statistical analysis method are used to analyze the demand of cereal agricultural social service (before planting and after harvesting). Shortage of funds is the biggest difficulty for farmer households on the demand of agricultural social service.
\end{abstract}

\section{Introduction}

The government has made a clear request to "improve the agricultural socialization service system". The third plenary session of the 17th central committee of the communist party of China first made the important position of agricultural socialization service system. In this paper, the analysis on the demand of agricultural social service (before planting and after harvesting) can lay a foundation for the research of the cereal agricultural social service[1]. It can provide support to improve and perfect the new mode research of cereal agricultural social service. It also can make the relevant policy recommendations for the government[2][3].

\section{Present Situation Investigation}

The survey was conducted in the field with a one-to-one questionnaire. We use typical sampling and random sampling to study the problem. The research objects are agricultural economies of all sizes, such as farmer households in middle-scale, farmer households in large-scale and cooperatives. The investigation on rice production and corn production was conducted in 9 villages in Dawa district, Panjin city, Liaoning province, and 12 villages in Changtu county of Tieling city, Liaoning province. A total of 272 questionnaires were completed, including 265 valid questionnaires, of which $97.43 \%$ were available.

\section{Descriptive Statistical Analysis}

The Analysis on the Demand of Agricultural Social Service Before Planting.

The results show that farmer households' cereal production has shifted from traditional artificial planting to outsourcing service, with $90 \%$ of corn and rice farmer households hiring outsourcing services. For labor-intensive production, such as soil preparation, planting, harvesting, etc., farmer households tend to outsourcing services, and for technology intensive production (spray insecticide, weeding, fertilizing, etc.)[4], farmer households hiring outsourcing proportion is low; In the sales process, farmer households hiring outsourcing proportion is also low. (See Table 1)Among rice farmer households, only a few farmer households in large-scale have outsourced services in the past two years. 
Table 1 The outsourcing degree of corn and rice farmer households Unit: \%

\begin{tabular}{ccccccc}
\hline & \multicolumn{3}{c}{ corn } & \multicolumn{3}{c}{ rice } \\
\cline { 2 - 6 } & $\begin{array}{c}\text { Small-sca } \\
\text { le }\end{array}$ & $\begin{array}{c}\text { Middle-sca } \\
\text { le }\end{array}$ & Large-scale & Small-scale & $\begin{array}{c}\text { Middle-sca } \\
\text { le }\end{array}$ & Large-scale \\
\hline $\begin{array}{c}\text { Soil preparation } \\
\text { Sprouting }\end{array}$ & 22.5 & 21.5 & 20.3 & 31.3 & 33.8 & 26.7 \\
$\begin{array}{c}\text { cultivation } \\
\text { Seeding }\end{array}$ & - & - & - & 2.5 & 35.1 & 0 \\
Fertilization & 22.1 & 20.8 & 17.6 & 25 & 21.6 & 16.2 \\
Weeding & 12.5 & 11.1 & 12.2 & 0 & 2.7 & 4.8 \\
Spraying & 11.3 & 10.4 & 10.8 & 0 & 2.7 & 4.8 \\
Insecticide & 12.9 & 13.9 & 14.2 & 2.5 & 4.1 & 6.7 \\
Harvest & 15.8 & 20.1 & 21.6 & 38.8 & 35.1 & 35.2 \\
Sale & 2.9 & 2.1 & 3.4 & 0 & 0 & 1.9 \\
\hline
\end{tabular}

Data source: statistical survey data

Agricultural capital purchase is the biggest burden for farmer households. According to the data, $24.83 \%$ of corn farmer households and $35 \%$ of rice farmer hou seholds have experienced financial stress in the process of purchasing agricultural capital. (See Figure 1) The shortage of funds will lead farmer households to pay back the grain by the end of the year, and the quality of the agricultural capital will not be selected and guaranteed, which will affect the quality of production and lead to a vicious circle. At the same time, farmer households report that they are afraid to buy back the low quality of agricultural capital, which will affect the income of a year. Therefore, there is a problem of insufficient purchasing power and poor quality of agricultural capital in terms of agricultural demand.

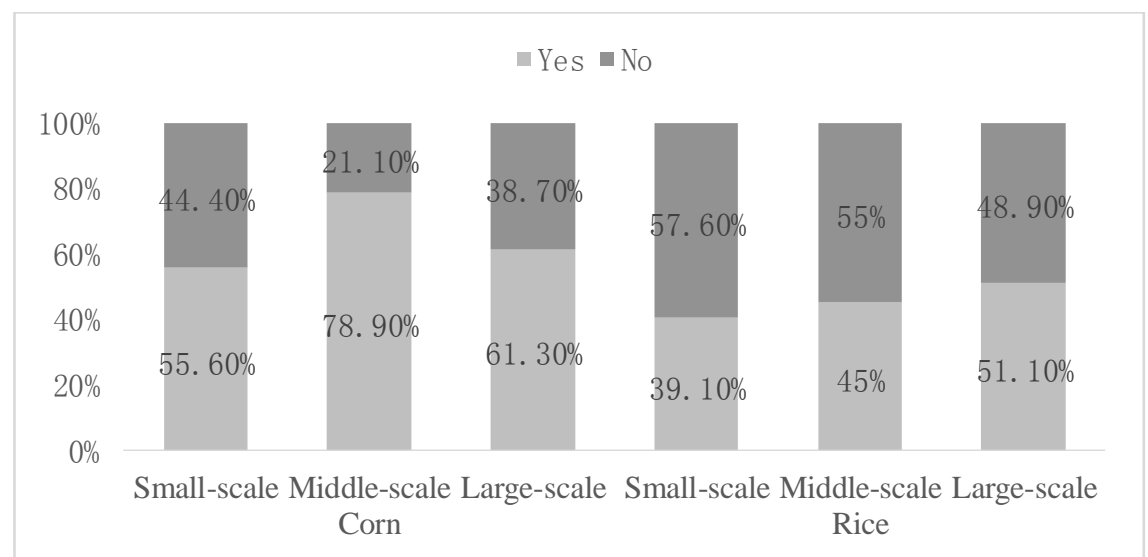

Figure 1 Whether farmer households are experiencing financial strain to purchase agricultural funds Data source: statistical survey data

The Analysis on the Demand of Agricultural Social Service After Harvesting.

According to the survey data, corn farmer households put more emphasis on air drying than rice farmer households.49.7\% of corn farmer households were exposed cereal to air drying, while only $13.3 \%$ of the rice farmer households put cereal to air drying. More rice farmer households pay for air drying than corn farmer households. (See figure 2) Many farmer households' storage places are empty houses or their own-built outdoor spaces, there are few specialized storage facilities for farmer households to storage their cereal. The cereal storage facilities built by the farmer 
households make the cereal loss rate high. But when asked if they would be willing to pay for air drying, most farmer households are unwilling. It can be seen that farmer households do not pay much attention to the air drying process, and do not want to spend more money and energy to build or rent the place.

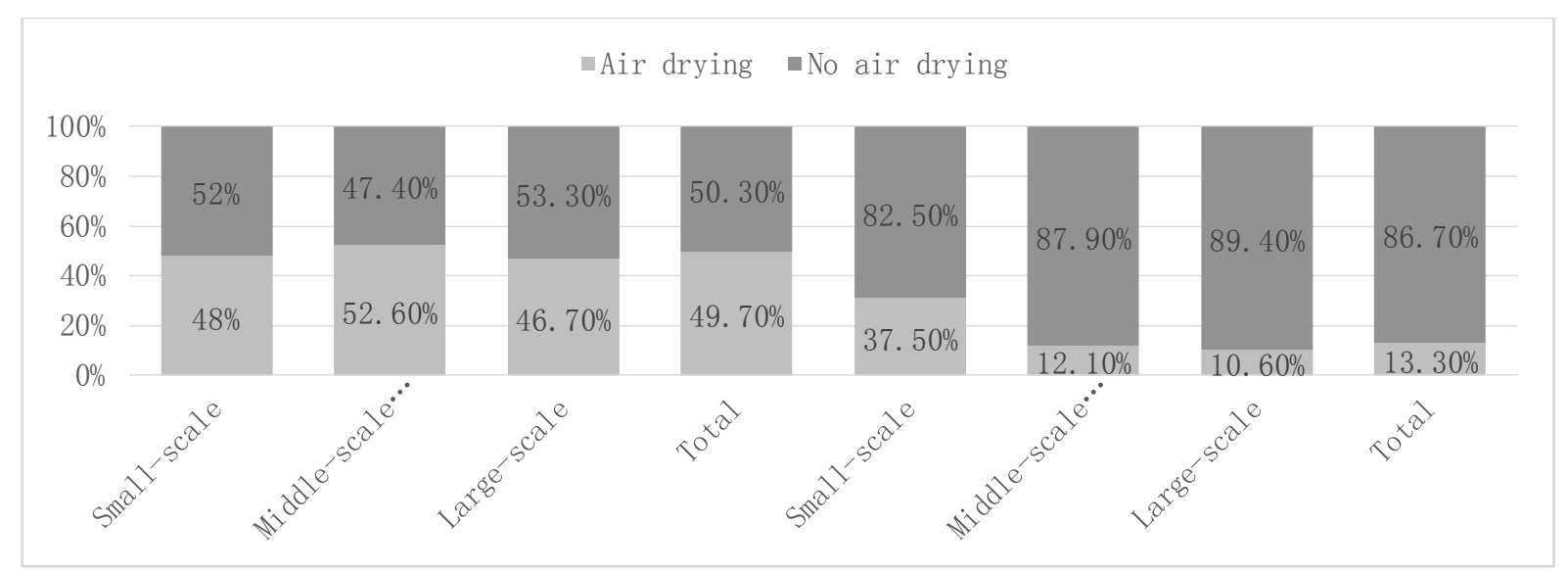

Figure 2 Whether the farmer households do the cereal air drying

Data source: statistical survey data

The survey results show that all farmer households do not have drying stove demand. Cereal drying stove is to preserve cereal for a long time (generally more than half a year), but farmer households usually sell it in the short term for profit. Without accurate safe water content detection and calculation, this risk is uncontrollable and can easily cause cereal loss.

The data shows that corn and rice farmer households often store cereal temporarily. $68.4 \%$ of the medium-scale farmer households are willing to deposit, while small-scale farmer households and large-scale farmer households prefer not to store. Most farmer households are willing to store because they expect cereal prices to rise in the future. (See table 2) For small-scale farmer households, they prefer to sell directly. For large-scale farmer households, the current storage facilities can not meet the demand of storage. Storage will impact their cash flow so most of them prefer to sell directly. The relationship between storage time and cereal wastage is investigated. The data shows that the longer the grain is stored, the lower the loss of grain, but the loss value is different in different time span. The storage facilities' quality is higher, the grain loss is lower.

Table 2 Different crops' purposes for storage Unit: \%

\begin{tabular}{ccc}
\hline Storage's purpose & Corn & Rice \\
\hline For higher price & 75.28 & 86.44 \\
Stored grain & 10.11 & 13.56 \\
Storage of feed & 14.61 & 0 \\
\hline
\end{tabular}

Data source: statistical survey data

Many farmer households sell grain to dealers who collect grain on the spot. In addition, some of the corn growers choose to send the corn to the local small drying tower to handle and sell it. Because in the Changtu area, the small-scale drying and selling enterprises are prevalent, they do not have high demand for the corn quality. They are closer to the farmer households and the transportation is more convenient. Farmer households sell their cereal to these enterprises because of its convenience. (See table 3). Farmer households have weak bargaining power. Medium-scale farmer households are more concerned about cereal sales than small-scale and large-scale farmer households. 
Table 3 Problems encountered by farmer households in the process of selling cereal Unit: \%

\begin{tabular}{ccccccc}
\hline & \multicolumn{3}{c}{ Corn } & \multicolumn{3}{c}{ Rice } \\
\cline { 2 - 7 } & $\begin{array}{c}\text { Small-sc } \\
\text { ale }\end{array}$ & $\begin{array}{c}\text { Middle-s } \\
\text { cale }\end{array}$ & $\begin{array}{c}\text { Large-sc } \\
\text { ale }\end{array}$ & $\begin{array}{c}\text { Small-scal } \\
\text { e }\end{array}$ & $\begin{array}{c}\text { Middle-s } \\
\text { cale }\end{array}$ & $\begin{array}{c}\text { Large-sca } \\
\text { le }\end{array}$ \\
\hline No problem & 75.8 & 47.4 & 60 & 72.5 & 48.5 & 51.1 \\
Inaccurate scale & 4.8 & 2.6 & 13.3 & 0 & 0 & 0 \\
Low price & 14.5 & 28.9 & 15.6 & 5 & 45.5 & 34 \\
Breaking contract & 0 & 0 & 2.2 & 0 & 0 & 0 \\
Manpower shortage & 1.6 & 0 & 2.2 & 2.5 & 0 & 0 \\
No transport & 3.2 & 5.3 & 4.4 & 7.5 & 6.1 & 8.5 \\
Money isn't given in & 0 & 10.5 & 2.2 & 0 & 0 & 4.3 \\
time & 0 & 5.3 & 0 & 12.5 & 0 & 2.1 \\
Others & 0.5
\end{tabular}

Data source: statistical survey data

\section{Conclusion}

We used the field survey method and descriptive statistical analysis method to understand the intention and characteristics of farmer households in Liaoning province. The results show that the farmer households have higher demand for the agricultural social service (before planting and after harvesting). Because of the cereal production methods from traditional artificial planting to outsourcing and the need of the High cost standard Air drying places. Shortage of funds is the biggest difficulty for farmer households on the demand of agricultural social service. Therefore, farmer households are expected to have a new mode of service to perfect their agricultural social service.

\section{Acknowledgement}

Supported by the foundation of General Project of Humanities and Social Science from Ministry of Education(14YJC790010), and Research on Economic and Social Development in Liaoning Province(20181slktqn-60)

\section{Reference}

[1] X.D.Cong and F.T.Yao: Review on the Status of Agricultural Socialization Service System. Northern Economy(2007)No.3, P61-62. (In Chinese)

[2] W.Y.Wang and Z.Y.Li: Establishing Modern Management Organization Model of Agricultural Production so as to Raise the Efficiency of Agricultural Organization. Journal of Shanxi Finance and Economics University(2001)No.1, P 40-43. (In Chinese)

[3] K.Q.Wu: Theoretical Analysis of Family Farms Economic, Review, (2013)No.6, P. 65-69. (In Chinese)

[4] Y.L.Li: Discussion on the related Theories of Agricultural Family Farm Advantages. Agricultural Economy,(2011)No.7, P 14-15. (In Chinese)

[5] Z.H.Yue and J.L.Yang: Current Situation, Problems and Policy Suggestions for Development of Family Farm in China, Research of Agricultural Modernization, (2013)No.4, P. 420-424. (In Chinese)

[6] W.Q.Zhao and Z.J.Bian: Analysis on the Operation Mode and Social Service Mechanism of Family Farm in ZheJiang Province, Agricultural Economy,(2012)No.4, P. 37-39. (In Chinese) 